\title{
Speed control in DC and AC drives
}

\author{
Reinel Beltrán Aguedo', Ania Lussón Cervantes², José Ricardo Nuñez Alvarez³, Yolanda Llosas \\ Albuerne $^{4}$ \\ 1,2Unidade Acadêmica do Cabo de Santo Agostinho (UACSA), Universidade Federal Rural de Pernambuco (UFRPE), \\ Cabo de Santo Agostihno, Pernambuco, Brazil \\ ${ }^{3}$ Energy Department, Universidad de la Costa (CUC), Barranquilla, Colombia \\ ${ }^{4}$ Electrical Engineering Department, Universidad Técnica de Manabí (UTM), Portoviejo, Ecuador
}

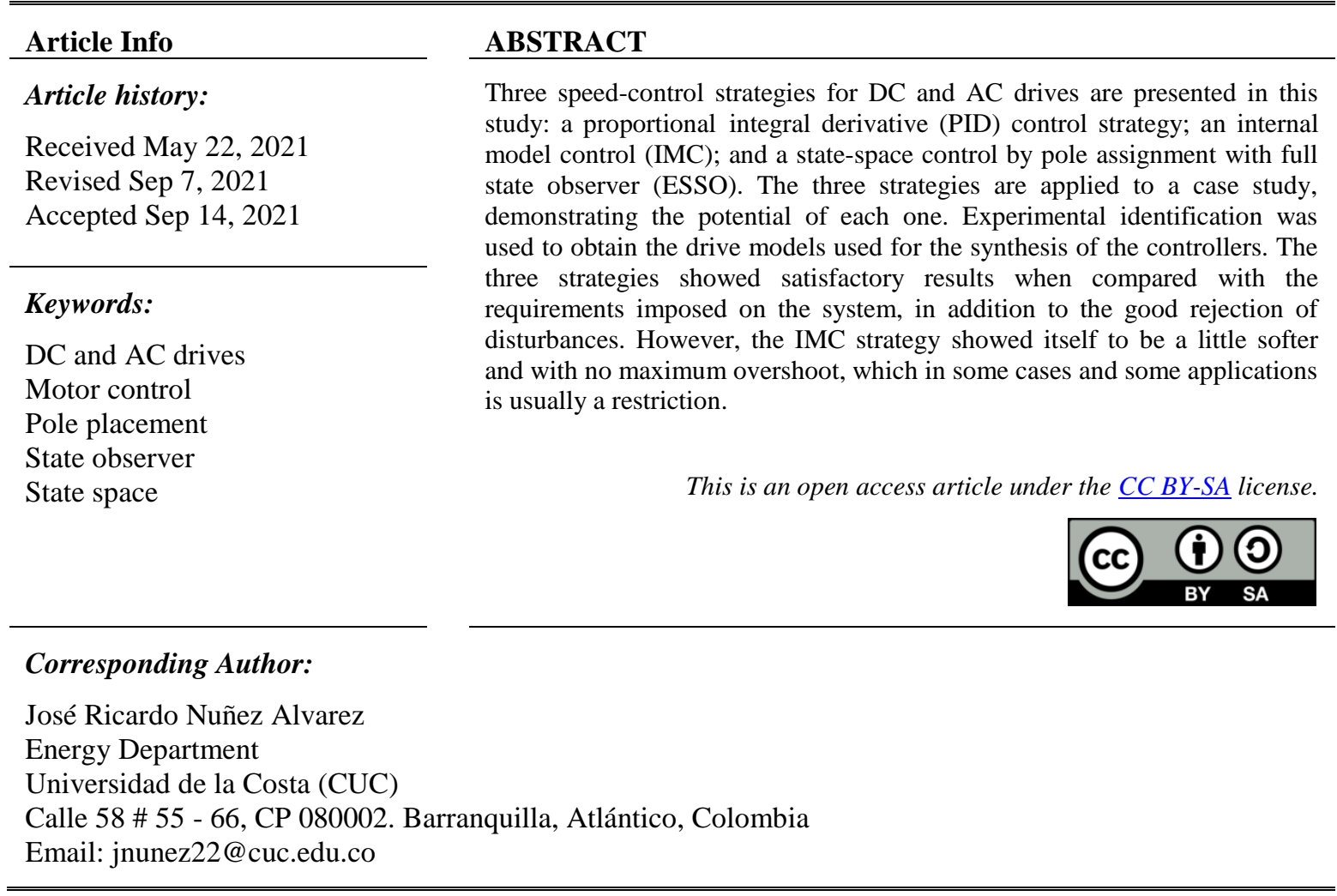

\section{INTRODUCTION}

The development of science and technology has also increased the quality, efficiency, and productivity of industrial services and processes. Modern industry has a wide variety of mechanisms that require speed control at different points in the production process. These mechanisms are a fundamental requirement for rotating electrical machines, basically direct current (DC) and alternating current (AC) motors. The DC motor offers facilities for speed control, which can be activated, for example, through the insertion of resistors in the armature, and through the variation of armature voltage or current in the field. These motors, despite their limitations in use, have enjoyed total hegemony in the industrial field for decades [1]. On the one hand, the cost of the AC motor is one-sixth of that of a DC motor of the same power and requires less maintenance. On the other, the motor provides no speed control facilities, which were at first achieved through the Ward Leonard system, given the impossibility of implementing a variable speed drive from an electrical system of constant voltage and frequencies; especially if the driver must be of high reliability and efficiency, have a wide range of speeds and moderate initial costs. For all those reasons, the DC motor has virtually been unrivaled for some years [2], [3].

Variable frequency converters have been introduced with the development of semiconductor devices, improving the technical characteristics of this type of drive to the point where it is superior to its nearest rivals because it permits high-precision, efficient, and quality speed regulation [4]-[6]. Thus, in recent 
years a wide variety of control techniques have been developed and applied, such as, for example, direct torque control (DTC) and field-oriented control (FOC), which have dominated the market for decades [7]-[9]. The proportional integral derivative (PID) controller has also been widely used in speed regulation, in combination with other techniques, such as fuzzy logic, neural networks, predictive control, and adaptive control, for proper tuning of such drivers [10]-[14]. Other more modern speed control techniques have also been applied, such as, for example, internal model control (IMC), control by pole assignment, model-based predictive control (MPC), and the use of state observers, among others [15]-[18].

The present work is based on the application of some control techniques in the speed control of DC and AC drives. Firstly, some theoretical aspects of PID control strategies, internal model control (IMC), and control by pole assignment are discussed in a general way. Since the objective of the control system is normally to ensure that the output follows a reference with zero error, it is, therefore, a type 1 follower system; finally, a complete order observer is considered in conjunction with the type 1 follower system. All the control strategies for speed control are simulated using Matlab and the results are validated in an experimental facility, including both the DC and the AC drive types.

\section{RESEARCH METHOD}

\subsection{PID control strategy}

The PID controller is the most popular and widely used in the industry, because of its low cost, simplicity, and the good dynamic behavior of the controlled process when properly tuned. It is estimated that about $95 \%$ of the control meshes use the PID and the proportional-integral (PI) [19], [20], which in its ideal form (ISA algorithm) is represented by (1).

$$
G_{c}(s)=\frac{U(s)}{E(s)}=K_{p}\left(1+\frac{1}{T_{i} s}+T_{d} s\right)
$$

Where $s$ is the Laplace complex variable, $U(s)$ the control signal, $E(s)$ the acting error, and $K_{P}, T_{i}$, and $T_{d}$ represent the proportional gain, the integrative, and the derivative time, respectively

Tuning a controller is a matter of determining the best combination of parameters $\left(K_{P}, T_{i}, T_{d}\right)$ so that the system will respond as desired. Among the various tuning methods, for example, are those based on the transient response, such as Ziegler-Nichols and Cohen-Coon, those based on comprehensive criteria, such as IAE and ITAE, and other methods based on computational and intelligent optimization techniques, such as genetic algorithms and fuzzy logic [21]-[23]. Such methods will not always guarantee acceptable determination of the parameters; however, they serve as a starting point for finer parametrical adjustments to satisfy the design conditions.

\subsection{IMC control strategy}

The internal model control (IMC) strategy considers the process model as part of the controller. The project is based on the cancellation of poles and zeros because the structure of the controller contains the inverse of the process model [24]-[26]. Figure 1 shows the typical block diagram of the IMC strategy.

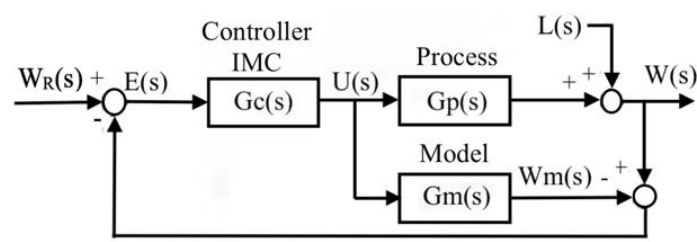

Figure 1. IMC control scheme [4]

Typically, the IMC controller design is done in two steps using the model factoring method.

Step 1 - Nominal behavior: The model is decomposed according to expression (2).

$$
G_{m}(s)=G_{m+}(s) G_{m-}(s)
$$

Where $G_{m+}(s)$ is the non-invertible portion, containing the zeros to the right of the complex half-plane, the unit gain and eventually the time delay, and $G_{m-}(s)$ is the invertible portion, containing the stable terms of the model. Thus, the ideal controller is the inverse of the invertible part of the model. 
Step 2 - Performance and robust stability: A low-pass filter is added to the ideal controller to generate a proper transfer function, strictly speaking, and to ensure that the controller is physically feasible. In addition, unwanted high-frequency behavior is avoided, and measurement noise is eliminated. The IMC controller is represented in (3).

$$
G_{c}(s)=\frac{1}{G_{m-}(s)} \frac{1}{\left(T_{f} s+1\right)^{n}}
$$

Where $n$ is the order of the filter and must be chosen in such a way as to guarantee that the controller is its own, which is usually equal to the order of the process whenever the problems of changes in the reference are addressed, and $T_{f}$ is the filter setting constant, which varies the response speed of the closed-loop system.

\subsection{Control strategy by pole placement}

The design of state feedback controllers assumes that all state variables are measurable and available for input feedback through a matrix of gains, K, with constant coefficients; see Figure 2. This feedback means that the poles may be in a closed loop in the desired position, as long as the system is in a completely controllable state [26].

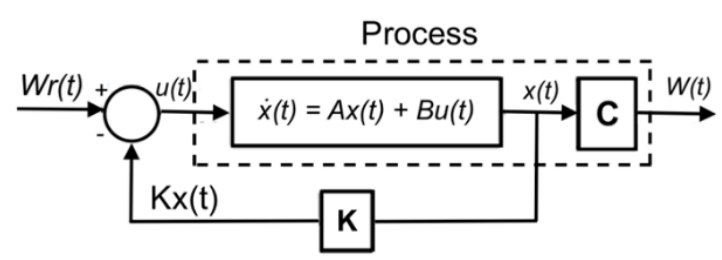

Figure 2. State feedback control scheme [27]

From the Figure 2 you get:

$$
\frac{W(s)}{W_{r}(s)}=C(s)[s I-A(s)+B(s) K]^{-1} B(s)
$$

Where $K=\left[k_{1}, k_{2}, \cdots, k n\right]$.

The closed-loop poles can be located by appropriate adjustment of the elements of the matrix $K$. If the desired location of the closed-loop poles is $p_{l}, p_{n}$, then the characteristic equation of the system given in (4) is:

$$
|s I-A(s)+B(s) K|=\left(s-p_{1}\right) \ldots\left(s-p_{n}\right)=0
$$

$K$ may be determined from the equality given in (5).

\subsection{Type 1 follower system}

In many practical applications, the output of the control system must follow the desired reference and electric drives are a typical case of such systems. If the process is of type 0 , then it will for example be unable to follow a step type reference with a null error. Thus, it is convenient to use a type 1 follower system so that the system can follow the reference with zero error. Figure 3 shows the basic principle of this type of system in which an integrator block is inserted in the direct path between the error comparator and the process [27].

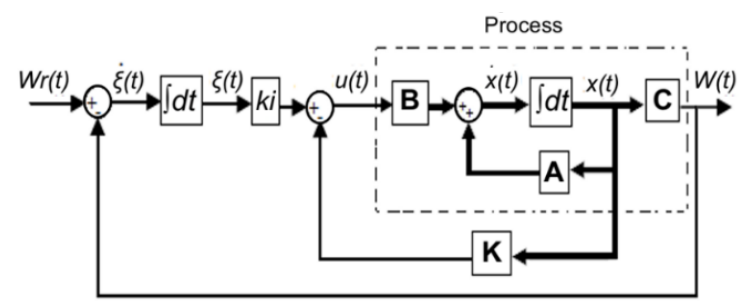

Figure 3. Type 1 follower system [27] 
For this configuration, (6) is considered.

$$
\dot{e}(t)=\hat{A} e(t)+\hat{B} u_{e}(t)
$$

Where $\hat{A}=\left[\begin{array}{cc}A & 0 \\ -C & 0\end{array}\right], \hat{B}=\left[\begin{array}{c}B \\ 0\end{array}\right]$, and $e(t)=\left[\begin{array}{cc}x(t) & -x(\infty) \\ \xi(t) & -\xi(\infty)\end{array}\right]$ is the error vector of order $(\mathrm{n}+1)$, and $u_{e}(t)=u(t)$ $-u(\infty)$ is the new control vector, given by $(7)$.

$$
\begin{aligned}
& u_{e}(t)=-\widehat{K} e(t) \\
& \text { where } \widehat{K}=\left[K-K_{i}\right]
\end{aligned}
$$

The objective of this system is to guarantee an asymptotically stable system using an acceptable determination of $\widehat{K}$. If the system is in a completely controllable state, then it is possible to determine such a matrix using the pole assignment approach.

\subsection{Follower system type 1 with state observer}

In practice, it is not common to have all the state variables available for feedback, so it is necessary to estimate them from the measurement of others (state observer). If all state variables are estimated, see Figure 4, then it is a complete order observer [27]. In (8) defines the observer's model.

$$
\tilde{x}(t)=A \tilde{x}(t)-B u(t)+K_{e}[W(t)-C \tilde{x}(t)]
$$

Where $K_{e}$ is the observer's earnings matrix, and the estimate of $x(t)$ is the vector of states

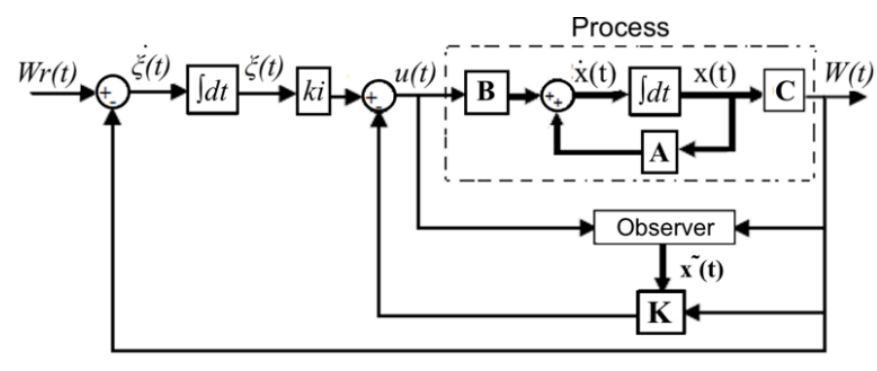

Figure 4. Type 1 follower system with state observer [27]

Starting from (8) we can arrive at (9), which defines the observer's error.

$$
\begin{aligned}
& \dot{e}(t)=\left(A-K_{e} C\right) e(t) \\
& \text { where } \dot{e}(t)=x(t)-\tilde{x}(t)
\end{aligned}
$$

If the system is completely observable, then it will be possible to determine $K_{e}$ so that $\left(A-K_{e} C\right)$ has arbitrarily desired eigenvalues, in such a way that the dynamic behavior of the error is asymptotically stable and sufficiently fast. $K_{e}$ may be determined in the same way as for $K$ in the assignment of poles.

\section{RESULTS AND DISCUSSION}

Next, the control strategies are synthesized, simulated, and experimentally validated in an experimental installation, including the two types of drives, DC and AC.

\subsection{Description of the experimental facility}

Figure 5 shows a block diagram of the experimental installation, which has a DC drive, consisting of a DC motor (5) of 10V / 1.5A and a maximum speed of $2500 \mathrm{rpm}$, a tachometer (6), model E5-600-5BZ-CV2.5 , coupled to the motor, and a power amplifier (4), to feed the DC motor and to give the speed command. There is likewise an AC drive, with an AC motor (8), three-phase induction, $80 \mathrm{~W} / 220 \mathrm{~V}$, and a maximum speed of $2460 \mathrm{rpm}$, with a frequency range of 3 to $60 \mathrm{~Hz}$ and a variable speed drive AF502-A40 (7), which is compliant with the constant $V / f$ relationship. The entire installation is controlled from a computer (1) and a 
SAD PCL818 (2) was used, internal to the computer, which has a maximum data transfer rate of $100 \mathrm{kHz}$. The input-output connections are made through the external module PCLD8115 (3). All signals are in a range from 0 to $10 \mathrm{~V}$ and data transfer is done by the program.

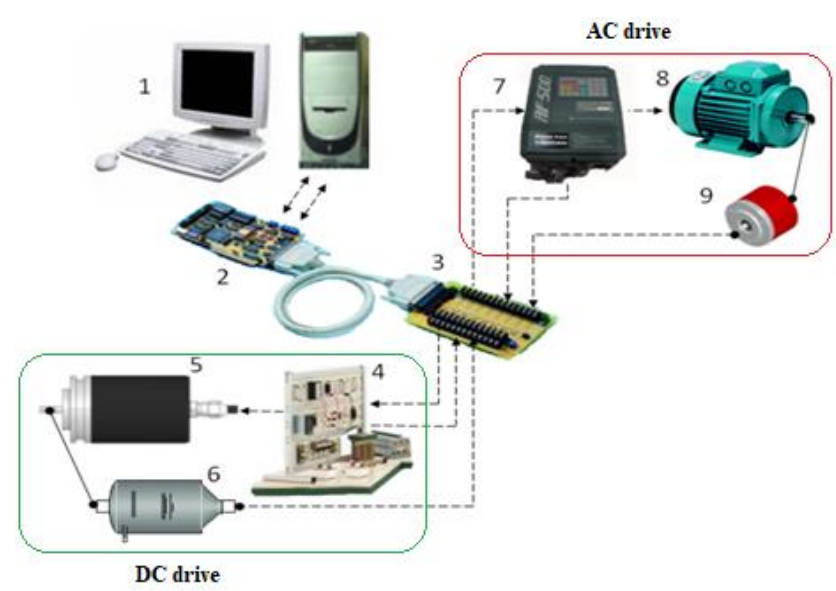

Figure 5. Experimental installation

\subsection{Models of DC and AC drives}

For the synthesis of the control strategies, the drives were modeled experimentally, applying a $10 \mathrm{~V}$ step as input, and as output, the speed was measured every 0.5 seconds. The input-output data were fed into the Matlab Identification Toolbox and the models for the DC and AC drives were obtained, given in (10) and (11), respectively. Figures 6 (a) and 6 (b) show the experimentally obtained responses and the responses from the model for both drives with an approximation of more than $96 \%$.

$$
\begin{aligned}
& G_{D C}(s)=\frac{250}{0.24 s+1} \\
& G_{A C}(s)=\frac{246.057}{0.125 s^{2}+0.8273 s+1}
\end{aligned}
$$

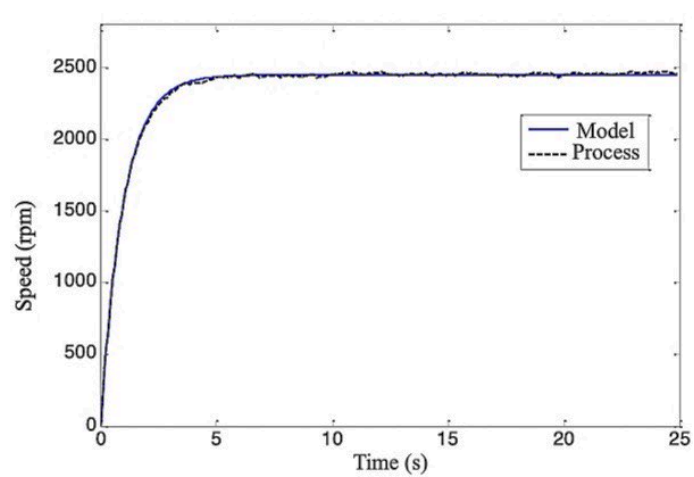

(a)

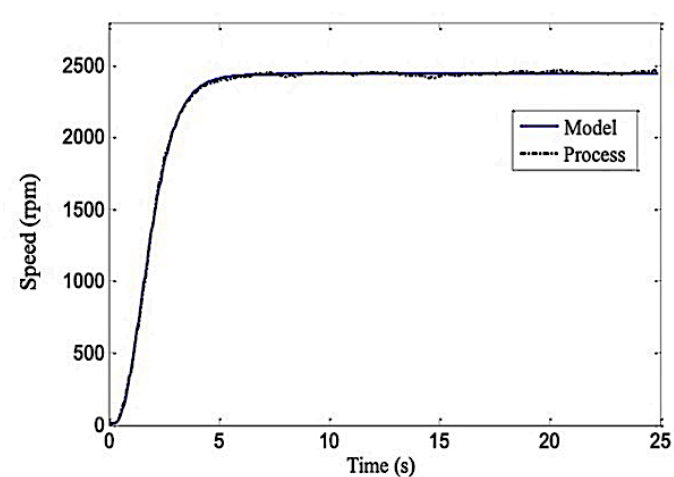

(b)

Figure 6. Model and process response: (a) DC drive, (b) AC drive

\subsection{PI control strategy for the DC drive}

The model given in (10) is a first-order model without delay, so a PI controller is sufficient to satisfy the design requirements. Its tuning, performed in Matlab, yielded the following:

$$
G_{P I_{D C}}(s)=0.0003435\left(1+\frac{1}{0.0244 s}\right)
$$


The response presented a maximum overshoot $\left(\mathrm{M}_{\mathrm{P}}\right)$ of $10 \%$ and settling time $\left(\mathrm{t}_{\mathrm{s}}\right)$ of approximately 1.52 seconds.

\subsection{IMC control strategy for DC drive}

Considering the model given in (10), the IMC controller for the DC drive is:

$$
G_{I M C_{-} D C}(s)=\frac{0.004(0.24 s+1)}{(0.4 s+1)}
$$

For which a first-order filter with an adjustment constant of 0.4 seconds was chosen.

\subsection{ESSO control strategy for the DC drive}

Expressing the model of the DC drive given in (10) in a representation in state variables, we have:

$$
\begin{aligned}
& \dot{x}=[-4.16] x+[1041.66] u \\
& y=[1] x+[0] u
\end{aligned}
$$

where $x$ is the state, and the output, and $u$ the control signal.

\subsection{Follower system type 1}

Examining the MCD controllability matrix.

$$
M C D=\left[\begin{array}{cc}
-4.16 & 1041.66 \\
-1 & 0
\end{array}\right]
$$

The range of MCD is 2 and its determinant anything other than zero when the system is in a completely controllable state. Assuming $\mathrm{M}_{\mathrm{P}}=10 \%$ and a peak time $\left(\mathrm{t}_{\mathrm{p}}\right)$ of 1 second, the desired characteristic is given by (16).

$$
S^{2}+4.6080 s * 15.1632=0
$$

The closed-loop characteristic is:

$$
|s I-\hat{A}+\hat{B} \widehat{K}|=s^{2}+\left(4.16+1041.66 k_{i}\right) s+1041.66 k_{i}
$$

Comparing (17) with (16), we can see that:

$$
\widehat{K}=\left[\begin{array}{ll}
4.279710^{-4} & 0.0146
\end{array}\right.
$$

which ensures that the system is asymptotically stable.

\subsection{Full order status observer}

Examining the OCD observability matrix:

$$
O C D=\left[\begin{array}{lll}
C^{\prime} & C^{\prime} A^{\prime} & C^{\prime} A^{\prime n-1}
\end{array}\right]=[1]
$$

Since the range of OCD is equal to 1 , the system is fully observable, choosing the desired from the observer as:

$$
s+5=0
$$

The observer's characteristic is:

$$
\left|s I-A+k_{e} C\right|=s+4.16+k_{e}=0
$$

Comparing (21) with (22), we can see that $k_{e}=0.84$.

\subsection{Simulation of the control strategies for the DC drive}

Figure 7 shows the performance of the three control strategies. First, a speed of $1200 \mathrm{rpm}$ is assumed, at 4 seconds the reference is changed to a speed of $2300 \mathrm{rpm}$, and at 8 seconds a disturbance in the speed of $100 \mathrm{rpm}$ is simulated. 


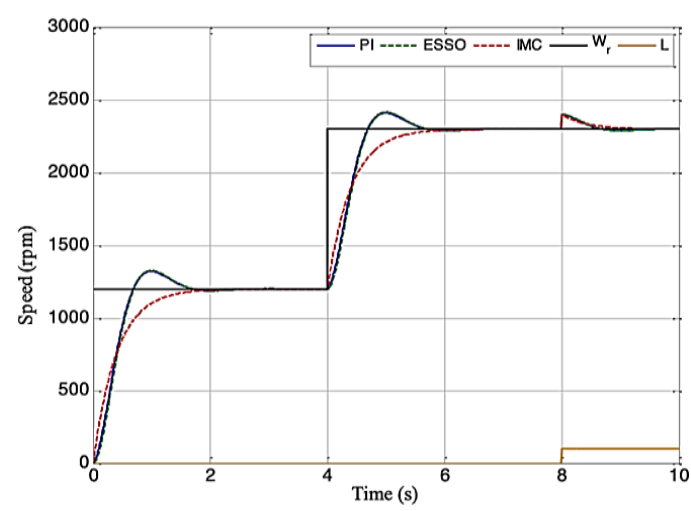

Figure 7. Control strategies in the DC drive

\subsection{PID control strategy for AC drive}

As the AC drive model is second order, a PID controller was used, and Matlab was also used for its tuning, resulting in the following controller:

$$
G_{P I D \_A C}=0.008\left(1+\frac{1}{5.5609 s}+0.01576 s\right)
$$

The response presents an $\mathrm{M}_{\mathrm{P}} \approx 10 \%$ and $\mathrm{at}$ 的 $\approx 1.6$ seconds.

\subsection{IMC control strategy for the AC Drive}

Considering (11), the IMC controller is given by:

$$
G_{I M C_{-} A C}(s)=0.0041\left(\frac{0.125 s^{2}+0.8273 s+1}{(0.2 s+1)^{2}}\right)
$$

A second-order filter was chosen with an adjustment constant of 0.2 seconds

\subsection{ESSO control strategy for the AC drive}

A state-space representation of (11) is:

$$
\begin{aligned}
& \dot{x}=\left[\begin{array}{cc}
-6.6184 & -8 \\
1 & 0
\end{array}\right] x+\left[\begin{array}{l}
1 \\
0
\end{array}\right] u \\
& y=\left[\begin{array}{ll}
0 & 1968.5
\end{array}\right] x
\end{aligned}
$$

Where the state vector $x=\left[\begin{array}{ll}x_{1} & x_{2}\end{array}\right]^{T}$

\subsection{Type 1 follower system}

Examining the MCA controllability matrix:

$$
M C A=\left[\begin{array}{ccc}
-6.6184 & -8 & 1 \\
1 & 0 & 0 \\
0 & -1968.5 & 0
\end{array}\right]
$$

The range of MCA is 3 and its determinant differs from zero. Assuming $M_{P}=10 \%$ and $t_{p}=1$ second, the dominant closed-loop poles are $p_{1,2}=-2.3029 \pm j 3.1400$. Choosing a third pole $p_{3}=-20$, the desired characteristic was:

$$
s^{3}+24.6052 s^{2}+107.2755 s+303.43=0
$$

The closed-loop characteristic equation was:

$$
s^{3}+\left(6.6184+k_{1}\right) s^{2}+\left(k_{2}+8\right) s-19668.5 k_{i}=0
$$


Comparing (27) with (26), it follows that:

$$
\widehat{K}=\left[\begin{array}{lll}
17.9868 & 99.2755 & 0.1541
\end{array}\right]
$$

Which thereby ensures that the system is asymptotically stable.

\subsection{Full order status observer}

Examining the $O C A$ observability matrix:

$$
O C A=\left[\begin{array}{cc}
0 & 1968.5 \\
1968.5 & 0
\end{array}\right]
$$

The range of $O C A$ is 2 and the nonzero determinant. Choosing the observer poles at $s_{1,2}=-5$, the desired characteristic is:

$$
s^{2}+10 s+25=0
$$

On the other hand, the characteristic equation of the observer is:

$$
s^{2}+\left(6.6184+1968.5 k_{e_{2}}\right) s+\left(8+1968.5 k_{e_{1}}+13028 k_{e_{2}}\right)=0
$$

Comparing (31) with (30),

\subsection{Simulation of control strategies for the AC drive}

Figure 8 shows the performance of the three control strategies. First, a steady-state speed of 1200 rpm was assumed, at 4 seconds the reference was changed to $2300 \mathrm{rpm}$, and at 8 seconds a disturbance in the speed of $100 \mathrm{rpm}$ was simulated.

As can be seen in Figure 9, the responses of the controlled system are satisfactory, in the PID and ESSO strategies the response was underdamped as designed, with $\mathrm{t}_{\mathrm{s}} \approx 1.6 \mathrm{~s}$. In the IMC strategy, the response showed no overshoot, was softer and therefore less aggressive, with a very similar ts to the PID and ESSO. When the system was disturbed, the three strategies satisfactorily performed rejection and the BMI did so more smoothly and with no tendency towards oscillation.

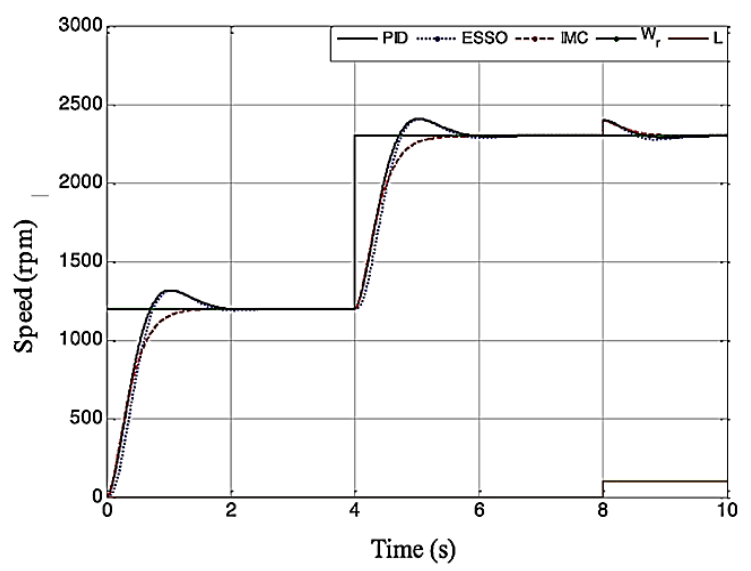

Figure 8. Control strategies in the AC drive

\section{VALIDATION AND DISCUSSION OF RESULTS}

A graphical interface for the validation was developed in LabWindows 6.5, allowing the selection of the drive and the control strategy, among other options, in Figure 9 and Figure 10. First, a reference speed of $1200 \mathrm{rpm}$ was proposed, and then it was changed to $2300 \mathrm{rpm}$. Figure 11 (a), Figure 11 (b), and Figure 11 (c) show the performance of the system controlled with the PI, IMC, and ESSO strategies, respectively, for the DC drive. Finally, Figure 12 (a), Figure 12 (b), and Figure 12 (c) show the performance of the control system using the PID, IMC, and ESSO strategies, respectively, for the AC drive. 


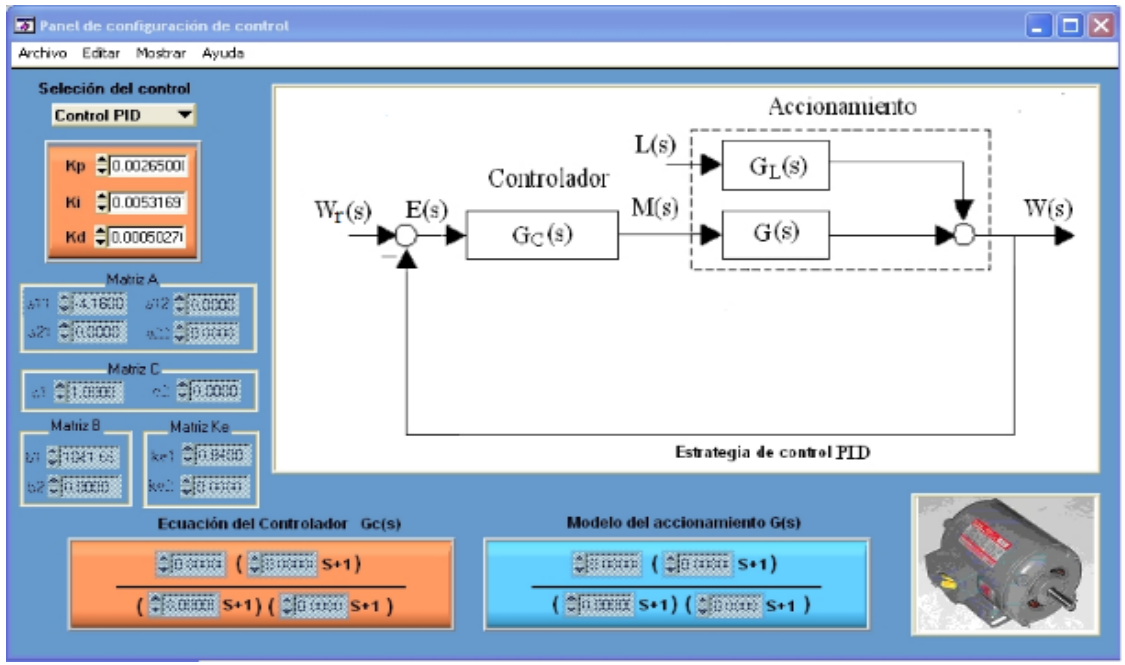

Figure 9. PID configuration panel for the DC drive

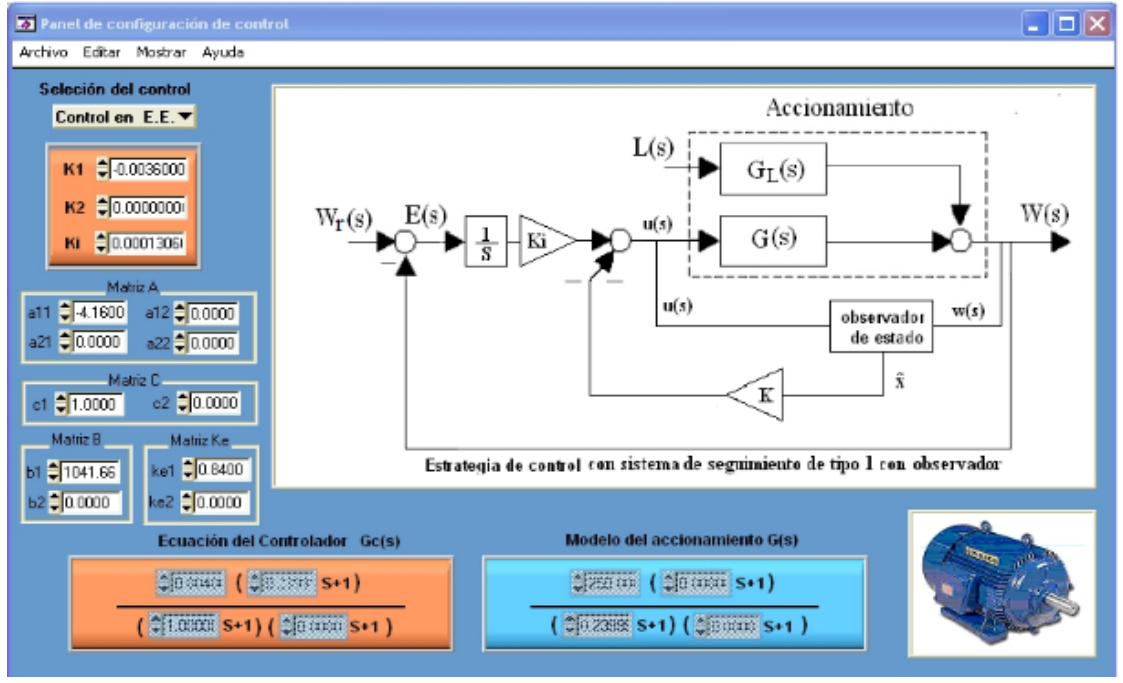

Figure 10. ESSO configuration panel for the AC drive

In all cases the results can be classified as satisfactory and in accordance with expectations. In the experiments carried out, the PI and PID control strategies showed better results at high speeds, since at low speeds the system started to oscillate, due to the mechanical characteristics of the experimental station, in which non-linearities and background noise can have more influence on the speed measurements of the control system.

The IMC control, moreover, has a broader speed control range in both electric drives, with values between 10 and $2500 \mathrm{rpm}$. For example, if we compare it with the PID variant, IMC showed a faster transient response and somewhat shorter settling times. However, it has been found that this control strategy sometimes tended to offer maximum overshoots during start-up when speeds below $500 \mathrm{rpm}$ were taken as the starting point.

The ESSO control strategy offered a lower speed control range on both drives, around 500 to 2500 rpm, in addition to a transient response with settling times that depended on the location of the desired closed-loop poles and the speed of the state observer. Moreover, this strategy tended to offer maximum overshoots during start-up by the above. Finally, it can be said that in both drives the responses were satisfactory, with small differences between the simulated and practical responses, which can be explained by non-molded dynamics and the non-linearities present in the physical system under investigation. 


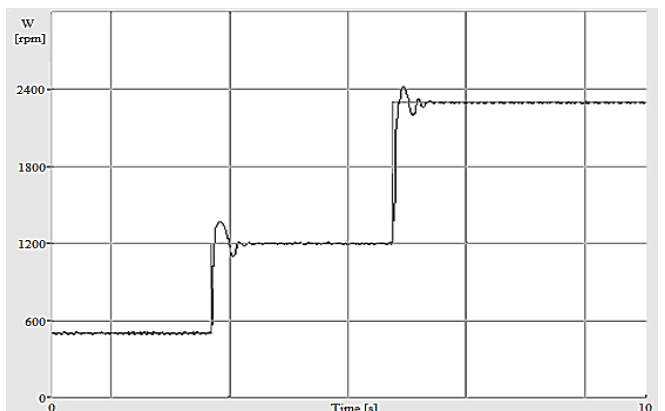

(a)

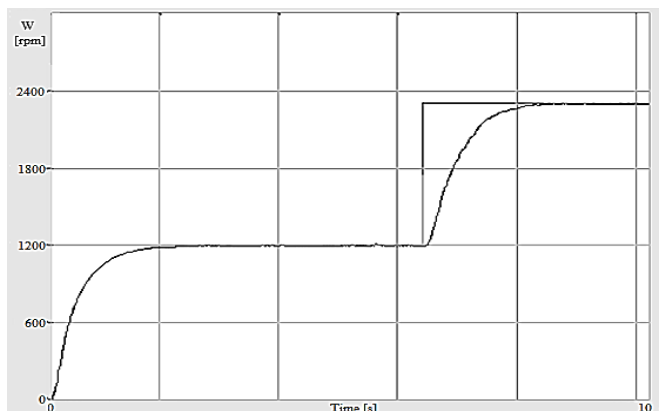

(b)

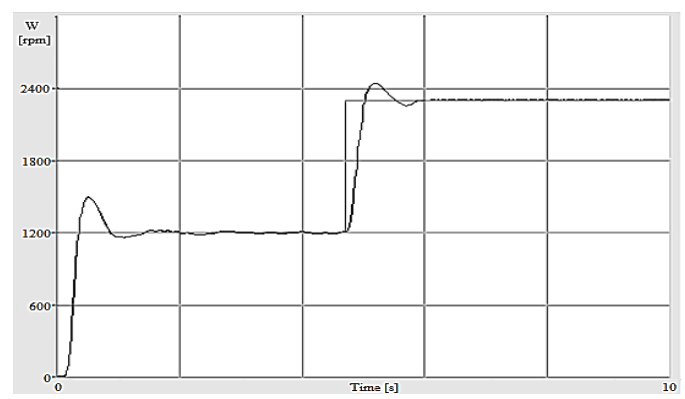

(c)

Figure 11. Controlled system performance using implemented strategies: (a) PI control strategy in the DC drive, (b) IMC control strategy in the DC drive, (c) ESSO control strategy in the DC drive

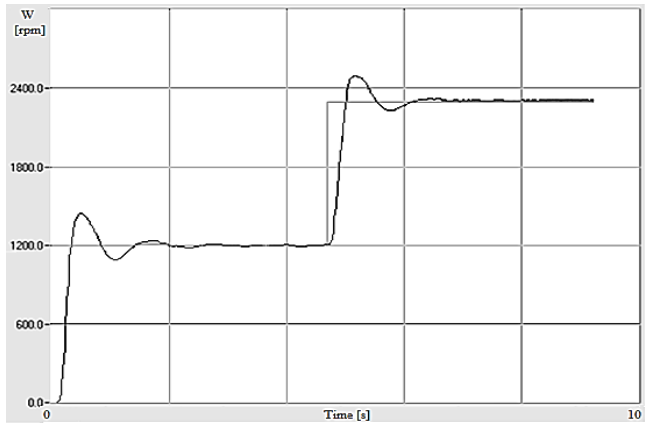

(a)

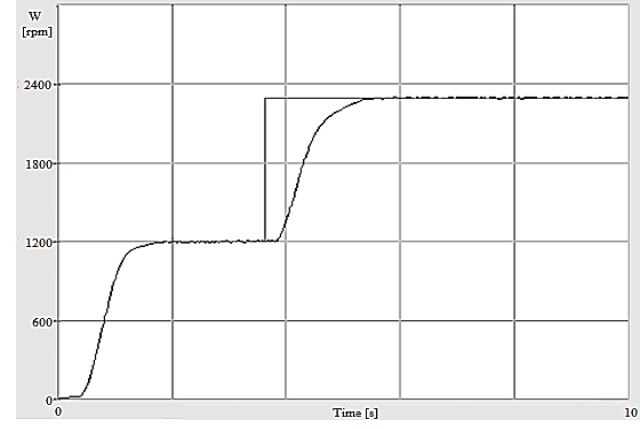

(b)

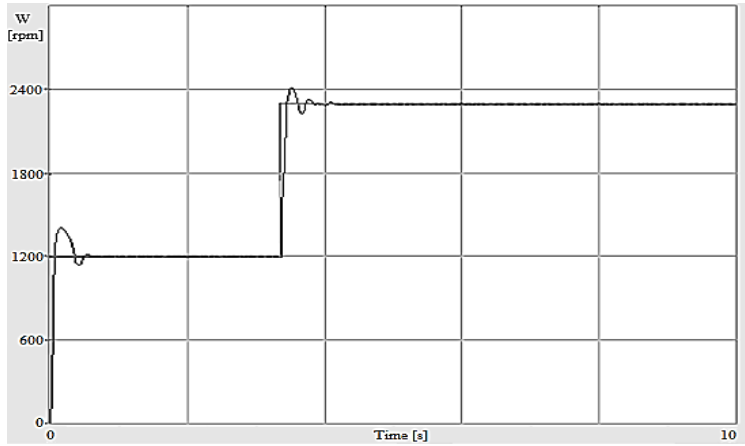

(c)

Figure 12. Control strategy: (a) PID control strategy in the AC drive, (b) IMC control strategy in the AC drive, (c) ESSO control strategy in AC drive 


\section{CONCLUSIONS}

Three control strategies for DC and AC drives have been synthesized. The drives have been modeled via experimental identification, where a first-order model was obtained for the DC drive and a second-order model for the AC drive, both without time delay. A graphical interface was developed in LabWindows 6.5 for the experimental validation, with which it was possible to configure all the instrumentation, choose the drive and the speed control strategy that was implemented, and it was also possible to set indicators for the speed and limits of alarms for the protection of the drive against possible overloads, low line voltage, short circuits, and locked rotors, for example. The drive, in addition to being protected by a security code and alarms, has an emergency stop button in case of tampering.

In general, it can be said that the response of the experimental system coincided with the simulated one. Moreover, the PI and PID control strategies presented better results for high speeds. The IMC control permitted a greater range of speed control on both electric drives, in addition to the less aggressive controller action. The ESSO strategy offered a lower speed control range on both electric drives and the transient response depended on the location of the desired closed-loop poles and the speed of the state observer.

\section{REFERENCES}

[1] R. A. Hasanjani, S. Javadi, and R. S. Nadooshan, "DC motor speed control by self-tuning fuzzy PID algorithm," Trans. of the Institute of Measurement and Control, vol. 37, no. 2, pp. 164-176, 2015. doi: $10.1177 / 0142331214535619$.

[2] S. N. Mahsahirun, N. R. Nik Idris, Z. M. Yusof, and T. Sutikno, "Fundamental elements of constant volt/hertz induction motor drives based on dSPACE DS1104 controller," International Journal of Power Electronics and Drive Systems IJPEDS, vol. 11, no. 4, pp. 1670-1685, 2020, doi: 10.11591/ijpeds.v11.i4.pp1670-1685.

[3] F. J. M. Álvarez, J. L. Blanco, J. L. T. Moreno, and A. G. Fernandez, "Modeling and multivariable control of the urban electric vehicle UAL-eCARM," Revista Iberoamericana de Automatica e Informatica Industrial, vol. 17, no. 2, pp 144-155, 2020, doi: 10.4995/riai.2019.12679.

[4] E. Guerrero, J. Linares, E. Guzman, H. Sira, G. Guerrero and A. Martinez, "DC motor speed control through parallel DC/DC buck converters," IEEE Latin America Transactions, vol. 15, no. 5, pp. 819-826, May 2017, doi: 10.1109/TLA.2017.7910194.

[5] S. Durand, B. Boisseau, N. Marchand, J. and J. F. G. Castellanos, "Event-based PID Control: application to a mini quadrotor helicopter," Journal of Control Engineering and Applied Informatics, vol. 20, no. 1, pp. 36-47, 2018.

[6] I. Inoan, and M. Abrudean, "Control of an induction motor using the relay method approach," Control Engineering and Applied Informatic, vol. 16, no. 3, pp. 13-22, 2014.

[7] A. Beltran, J. Rambo, H. Azcaray, K. Santiago, M. Calixto, and E. Sarmiento, "Simulation and control of the velocity and electromagnetic torque of a three-phase induction motor: An electric vehicles approach," Revista Iberoamericana de Automatica e Informatica Industrial, vol. 19, no. 3, pp. 308-320, 2019.

[8] N. E. Ouanjli et al., "Modern improvement techniques of direct torque control for induction motor drives-A review," Protection and Control of Modern Power Systems," vol. 4, no. 1, pp. 1-12, 2019, doi: 10.1186/s41601019-0125-5.

[9] O. S. Bhatti, M. Rizwan, P. S. Shiokolas, and B. Ali, "Genetically optimized ANFIS-based PID controller design for posture-stabilization of self-balancing-robots under depleting battery conditions," Control Engineering and Applied Informatics, vol. 21, no. 4, pp. 22-33, 2019.

[10] Q Wu, X Li, M Zhang, L Pang, and J Li, "Fast parameter identification of permanent magnet synchronous motor for electric vehicles," Control Engineering and Applied Informatics CEAI, vol. 21, no 4, pp. 24-42, 2019.

[11] H. S. Sridhar, P. Hemanth, Pavitra, H. V. Soumya, and B. G. Joshi, "Speed control of BLDC motor using soft computing technique," International Conference on Smart Electronics and Communication ICOSEC, 2020, pp. 1162-1168, doi: 10.1109/ICOSEC49089.2020.9215417.

[12] V. S. Sousa, J. J. C. Eras, A. S. Gutierrez, and M. J. C. Ulloa, "Assessment of the energy efficiency estimation methods on induction motors considering real-time monitoring," Measurement, vol. 136, pp. 237-247, 2019, doi: 10.1016/j.measurement.2018.12.080.

[13] V. Felipe et al., "Permanent magnet assisted synchronous reluctance motors: A new advance in electric motors development," Ingeniería, investigación y tecnología, vol. 19, no. 3, pp. 267-277, 2018, doi: 10.22201/fi.25940732e.2018.19n3.023.

[14] J. R. Nuñez et al., "Design of a fuzzy controller for a hybrid generation system," IOP Conference Series: Materials Science and Engineering, vol. 844, no. 012017, pp. 1-20, 2020, doi: 10.1088/1757-899X/844/1/012017.

[15] N. Farah, M. H. N. Talib, Z. Ibrahim, J. M. Lazi, and M. Azri, "Self-tuning fuzzy logic controller based on TakagiSugeno applied to induction motor drives," International Journal of Power Electronics and Drive Systems IJPEDS, vol. 9, no. 4, pp. 1967-1675, 2018, doi: 10.11591/ijpeds.v9.i4.pp1967-1975.

[16] N. N. Baharudin, and S. M. Ayob, "Brushless DC motor drive control using single input fuzzy PI controller (SIFPIC)," IEEE Conference on Energy Conversion CENCON, 2015, pp. 13-18, doi: 10.1109/CENCON.2015.7409506.

[17] J. Talla, V. Q. Leu, V. Śmídl, and Z. Peroutka, "Adaptive speed control of induction motor drive with inaccurate model," IEEE Transactions on Industrial Electronics, vol. 65, no. 11, pp. 8532-8542, 2018, doi: 10.1109/TIE.2018.2811362. 
[18] M. R. Devi, and L. Premalatha, "Soft computing technique of bridgeless SEPIC converter for PMBLDC motor drive," International Journal of Power Electronics and Drive Systems IJPEDS, vol. 9, no. 4, pp. 1503-1509, 2018, doi: 10.11591/ijpeds.v9.i4.pp1503-1509.

[19] K. J. Aström, and T. Hägglund, PID controllers, Book 2nd edition, The International Society for Measurement and Control: Instrument Society of America, 1995.

[20] K. J. Aström, and T. Hägglund, Advanced PID control, Book 488, Publishing Pearson Education, 2009.

[21] K. Aseem, and S. S. Kumer, "Closed loop control of DC-DC converters using PID and FOPID controllers," International Journal of Power Electronics and Drive Systems, vol. 11, no. 3, pp. 1323-1332, 2020, doi: 10.11591/ijpeds.v11.i3.pp1323-1332.

[22] O. Bashir, X. Rui, L. K. Abbas, and J. Z. Zhang, "Ride comfort enhancement of semi-active vehicle suspension based on SMC with PID sliding surface parameters tuning using PSO," Control Eng. and Applied Informatics, vol. 21, no. 3, pp. 51-62, 2019.

[23] A. A. S. León, and J. R. N. Alvarez, "1D convolutional neural network for detecting ventricular heartbeats," IEEE Latin America Transactions, vol. 17, no. 12, pp. 1970-1977, 2019, doi: 10.1109/TLA.2019.9011541.

[24] M. A. Ibrahim, A. K. Mahmood, and N. S. Sultan, "Optimal PID controller of a brushless dc motor using genetic algorithm," International Journal of Power Electronics and Drive Systems IJPEDS, vol. 10, no. 2, pp. 822-830, 2019, doi: 10.11591/ijpeds.v10.i2.822-830.

[25] A. Abdallah, A. Bouchetta, O. Boughazi, A. Baghdadi, and L. K. Bousserhane, "Double star induction machine using nonlinear integral backstepping control," International Journal of Power Electronics and Drive Systems IJPEDS, vol. 10, no. 1, pp. 27-40, 2019, doi: 10.11591/ijpeds.v10.i1.pp27-40.

[26] J. Nuñez, I. F. Benítez Pina, A. Rodríguez Martínez, S. Díaz Pérez, and D. Luiz de Oliveira, "Tools for the implementation of a SCADA system in a desalination process," IEEE Latin America Transactions, vol. 17, no. 11, pp. 1858-1864, 2019, doi: 10.1109/TLA.2019.8986424.

[27] K. Ogata, Modern control engineering, Fifth Edition, Publisher Prentice Hall US, 2010.

\section{BIOGRAPHIES OF AUTHORS}

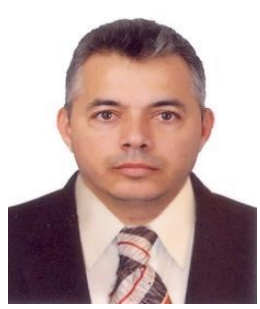

Reinel Beltrán Aguedo. He has a degree in Automatic Control Engineering from the Universidad de Oriente, Cuba (1994), a PhD in Systems Control from the Universidad Nacional del Sur, Argentina (2003). He is currently an adjunct professor at the Engineering Campus (UACSA) of the Federal Rural University of Pernambuco (UFRPE), Pernambuco, Brazil. E-mail reinel.beltran@ufrpe.br; Scopus ID 6507608633; ORCID 0000-0001-8803-2397; Google Scholar 99YdxZQAAAAJ; ID Publons S-7981-2017.

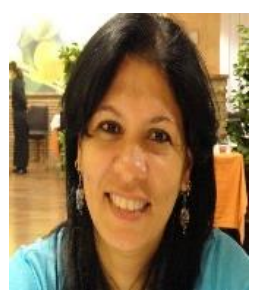

Ania Lussón Cervantes. She has a degree in Automatic Control Engineering from the Universidad de Oriente, Cuba (1994), a PhD in Systems Control from the Universidad Nacional del Sur, Argentina (2002). She is currently an adjunct professor at the Engineering Campus (UACSA) of the Federal Rural University of Pernambuco (UFRPE), Brazil. E-mail ania.lusson@ufrpe.br; Scopus ID 57191920359; ORCID: 0000-0002-5428-8973; Google Scholar 5GbGBKkAAAAJ; ID Publons AAU-8338-2021.

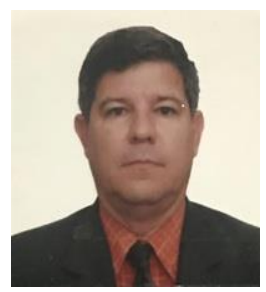

José Ricardo Núñez Álvarez. Full Time Professor at the Department of Energy at the Universidad de la Costa (CUC), Barranquilla, Colombia. He obtained the title of Electrical Engineer in 1994. Master of Science in Electrical Engineering in 2003 and Master of Science in Automation in 2014. E-mail jnunez22@cuc.edu.co; Scopus ID 57222123252; ORCID 00000002-6607-7305; Google Scholar M5TXcO4AAAAJ; ID Publons B-8716-2019.

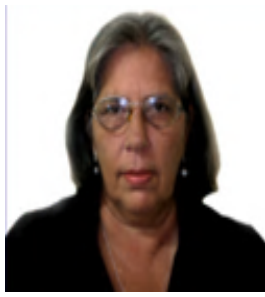

Yolanda Llosas Albuerne. Full-time principal professor in the Department of Electricity of the Technical University of Manabí (UTM), Portoviejo Ecuador. She graduated from Electrical Engineering in Automatic Control in 1979 at the Universidad de Oriente, Cuba, she defended the doctorate in Technical Sciences in 1992. E-mail: yolanda.llosas@utm.edu.ec; Scopus ID 56469714000; ORCID: 0000-0002-5713-0565; Google Scholar AP1MR9sAAAAJ. 